\title{
Intermittent hypoxia treatment alleviates memory impairment in the 6-month-old APPswe/PS1dE9 mice and reduces amyloid beta accumulation and inflammation in the brain
}

\author{
Xiangpei Yue ${ }^{1}$, Yanzhao Zhou ${ }^{1}$, Meng Qiao ${ }^{1}$, Xingnan Zhao ${ }^{1}$, Xin Huang ${ }^{1}$, Tong Zhao ${ }^{1}$, Xiang Cheng ${ }^{1}$, \\ Ming Fan ${ }^{1}$, Yongqi Zhao ${ }^{1}$, Ruoli Chen ${ }^{2^{*}}$ and Lingling Zhu ${ }^{1,3,4,5^{*}}$
}

\begin{abstract}
Background: Alzheimer's disease (AD) is a progressive, degenerative, and terminal disease without cure. There is an urgent need for a new strategy to treat AD. The aim of this study was to investigate the effects of intermittent hypoxic treatment (IHT) on cognitive functions in a mouse model of $A D$ and unravel the mechanism of action of IHT.

Methods: Six-month-old APPswe/PS1dE9 (APP/PS1) male mice were exposed to hypoxic environment $\left(14.3 \% \mathrm{O}_{2}\right) 4$ h/day for 14 days or 28 days. Cognitive functions were measured by Morris water maze test after either 14 days or 42 days of interval. Thereafter the distribution of amyloid plaque and microglial activation were determined by mouse brain immunohistochemistry, while the amyloid beta (A $\beta$ ) and inflammatory cytokines were measured by ELISA and Western Blot. Microarray was used for studying gene expressions in the hippocampus.

Results: $I H T$ for 14 days or 28 days significantly improved the spatial memory ability of the 6-month-old APP/PS1 mice. The memory improvement by 14 days IHT lasted to 14 days, but not to 42 days. The level of A $\beta$ plaques and neurofilament accumulations was reduced markedly after the IHT exposure. IHT reduced the pro-inflammatory cytokines IL-1 $\beta$, IL-6 levels, and $\beta$-secretase cleavage of APP processing which implies reduced A $\beta$ production. Microarray analysis revealed a large number of genes in the hippocampus were significantly altered which are known to be metabolism-regulated genes.
\end{abstract}

Conclusions: This study provides evidence of the beneficial effect of IHT on the progression of AD by alleviating memory impairment, reducing A $\beta$ accumulation and inflammation in the brain. IHT can be developed as a novel measure to relieve the progression of AD by targeting multiple pathways in the AD pathogenesis.

Keywords: Alzheimer's disease, APPswe/PS1dE9 mice, Intermittent hypoxia treatment, Amyloid beta, BACE1, Neuroinflammation, Gene expression

\footnotetext{
*Correspondence: r.chen@keele.ac.uk; linglingzhuamms@126.com ${ }^{2}$ Institute for Science and Technology in Medicine, School of Pharmacy, Keele University, Kelle, UK

${ }^{5}$ Anhui Medical University, Hefei 230022, Anhui, China

Full list of author information is available at the end of the article
}

\section{Background}

Intermittent hypoxia is broadly defined as repeated episodes of hypoxia interspersed with episodes of normoxia [1]. Since the 1940s, intermittent hypoxia treatment (IHT) has been commonly used for training pilots, mountaineers, and athletes to improve permits use, sharing, adaptation, distribution and reproduction in any medium or format, as long as you give appropriate credit to the original author(s) and the source, provide a link to the Creative Commons licence, and indicate if changes were made. The images or other third party material in this article are included in the article's Creative Commons licence, unless indicated otherwise in a credit line to the material. If material is not included in the article's Creative Commons licence and your intended use is not permitted by statutory regulation or exceeds the permitted use, you will need to obtain permission directly from the copyright holder. To view a copy of this licence, visit http://creativecommons.org/licenses/by/4.0/. The Creative Commons Public Domain Dedication waiver (http://creativeco mmons.org/publicdomain/zero/1.0/) applies to the data made available in this article, unless otherwise stated in a credit line to the data. 
performance by way of adaptation to reduce the oxygen environment [2-4]. In recent years, more and more research evidenced that IHT can be beneficial for the treatment of a wide range of diseases such as chronic heart and lung diseases, hypertension [5], iron-deficiency anemia [6], Parkinson's disease, and ischemic coronary artery diseases [7-9]. As such, IHT has been applied for the treatment and prevention of chronic bronchial diseases (e.g., asthma) as a non-invasive, auxiliary treatment, via initiating a cascade of beneficial adaptive responses without adverse effects [10-14]. The cascade of IHT includes multiple changes in metabolic pathways and inflammatory responses and promotes angiogenesis and neurogenesis, which are evident at various levels, from systemic down to cellular [15-19]. However, the consequences of IHT on the pathological processes of Alzheimer's disease (AD) are not defined.

$\mathrm{AD}$ is characterized by a progressive impairment of memory and other cognitive function [20, 21]. The incidence of AD is $15 \%$ among those 65 years and older and is close to $50 \%$ for those aged over 85 years [22]. The pathological hallmarks are extracellular amyloid beta $(A \beta)$ accumulation and intracellular neurofibrillary tangles (NFTs), which leads to synaptic degeneration, neuroinflammation, eventually neuronal death [23-28]. Despite the significant progress that has been made toward understanding the genetic and molecular biological basis of AD in recent years, psychosocial and family nursing interventions, combined with acetylcholinesterase inhibitors and neuroprotective agents, are mainly used to alleviate AD symptoms, and there is no cure for AD yet [29]. It is critical to discover novel approaches, which could target multiple key pathways in the pathogenesis of $\mathrm{AD}$, to halt the progression of AD.

In this context, we first validated and confirmed the in vivo effects of IHT on cognitive functions in APPswe/PS1-dE9 (APP/PS1) mice. APP/PS1 are double transgenic mice expressing a chimeric mouse/human amyloid precursor protein (Mo/HuAPP695swe) and a mutant human presenilin 1 (PS1-dE9), both directed to central nervous system neurons [30]. Both mutations are associated with early-onset $\mathrm{AD}$ [31]. We found that IHT alleviated the cognitive deficits, and inhibited $A \beta$ production thus reducing $A \beta$ fibrils in 6-month-old APP/PS1 mice, suggesting that IHT is an effective approach for inhibiting the onset of $A \beta$ deposition. Furthermore, we identified the expression of a large number of genes in the mouse brain of the IHT group were altered, most of which were known to be metabolism-regulated genes or be enriched in p53 pathway.

\section{Methods}

\section{Animals}

Male, 8-week-old APP/PS1 mice and C57/BL6J wildtype mice were purchased from Beijing Huafukang Bioscience Co. Ltd. (Beijing, China) and were housed at a constant temperature under a 12-h light-dark cycle with unlimited access to standard diet and water in the animal house of the Beijing Institute of Basic Medical Sciences. All protocols involving the use of animals were conducted in accordance with the Institutional Animal Care and Use Committee of the Institute of Basic Medical Science. The mice were randomly assigned and all experiments were carried out double-blind.

\section{IHT exposure}

The 6-month-old mice were placed in a decompression chamber (model: DYC-DWI; Fenglei, China) and were exposed to a hypoxic environment $\left(14.3 \% \mathrm{O}_{2}\right.$, equal to $3000-\mathrm{m}$ high altitude, at the velocity of $5 \mathrm{~m} / \mathrm{s}$ in 10 $\min ) 4 \mathrm{~h}$ per day for 14 days or 28 days $(n=10-12$ per group). The control groups were placed in the chamber under normoxic conditions at the same time as the treatment groups and by the same experimenter. Routine blood test which measures the cells in the body through the blood was examined by an automated blood analyzer (SYSMEX, Kobe, Japan). Physiological indexes such as heart rate, breath rate, diastolic blood pressure (DBP), systolic blood pressure (SBP), mean blood pressure (MBP), and partial pressure of oxygen $\left(\mathrm{PO}_{2}\right)$ were measured by a noninvasive pulse oximeter for animals (MouseOx ${ }^{\circledR}$ Plus pulse oximeter, PA, USA).

\section{Morris water maze test}

The test was performed using a black circular pool of $122 \mathrm{~cm}$ in diameter that was divided into 4 equal quadrants. A transparent circular platform $\left(10 \mathrm{~cm}^{2}\right)$ was submerged $1.5 \mathrm{~cm}$ beneath the water surface. The water temperature was adjusted to $19-22{ }^{\circ} \mathrm{C}$. The water maze activity was recorded using a video camera and analyzed with a professional analysis system (ANY-maze system, Dublin, Ireland). The experimental procedure includes the platform trial and the probe trial. The platform trial was performed for five consecutive days with a platform beneath the water, to measure the mice's ability of learning and memory. Thereafter, the platform was removed from the pool, and the probe trial was performed to measure the memory retention of the spatial position of the platform ( $n=10-12$ per group).

\section{Immunohistochemistry}

After the behavior test, the mice were deeply anesthetized with sodium pentobarbital $(50 \mathrm{mg} / \mathrm{kg}$, i.p.) and 
then were perfused transcardially with $0.9 \%$ sodium solution, followed by $4 \%$ paraformaldehyde (Solarbio, Beijing, China). Their brains were immediately removed, then rear-fixed while dehydrating with 30\% sucrose-formaldehyde solution at $4{ }^{\circ} \mathrm{C}$ until they sank to the bottoms of $5 \mathrm{ml}$ centrifuge tubes. The brains were embedded by optimal cutting temperature compound (O.C.T. compound) (SAKURA, CA, USA) and then were cut into $40-\mu \mathrm{m}$-thick coronal sections ( $n=6$ per group).

Polink-2 puls ${ }^{\circledR}$ Polymer HRP detection system (PV9001/ PV9002, ZSGB-BIO, Beijing, China) was used to determine the distribution of amyloid plaques, neurofilament accumulations, and ionized calcium-binding adaptor molecule 1 (IBA1) immunoreactivity in mice brains. Briefly, the sections were pre-treated using heat mediated antigen retrieval with sodium citrate buffer ( $\mathrm{pH} 6$, epitope retrieval solution 1) for 20 mins, then the sections were incubated in 3\% hydrogen peroxide deionized water for 10 min to block endogenous peroxidase. After that, the sections were incubated respectively with primary antibody: mouse anti-amyloid precursor protein (APP)/A $\beta$ (1:100, Cell Signaling Technology; USA), mouse anti-Neurofilament-L (1:100, Cell Signaling Technology; USA), and rabbit anti-IBA1 (1:200, WAKO, Japan), $4{ }^{\circ} \mathrm{C}$ overnight. Horseradish enzyme-labeled anti-mouse IgG (or antirabbit IgG) polymers were added to detect the primary antibodies and were visualized using an HRP detection system. Diaminobenzidine (DAB) (ZSGB-BIO, ZII-9017, Beijing, China) was used as the chromogen. The section was then rinsed with tap water, re-dyed, dehydrated, transparent, and sealed. Images have been captured by a pathological section scanner (NDP, Japan). The number of $\mathrm{A} \beta$-positive plaques in the cortex and hippocampus formation was calculated using Image Pro Plus 6.0 software. Briefly, 20 consecutive sections of each mouse cortex and hippocampus were imaged together and the areas and the total counts of $A \beta$-positive plaques in sections per six mouse brains of each group were determined using the software. The level of neurofilament accumulations and IBA1 immunoreactivity was measured by using the mean optical density of DAB staining.

The histofluorescence assay to detect the glycocalyx microvasculature was made with $10 \mu \mathrm{g} / \mathrm{ml}$ of Fluorescein Lycopersicon esculentum (Lectin) (Vectorlabs, Burlingame, USA). Brain slices were first washed three times with PBS and then incubated overnight with lectin $(10 \mu \mathrm{g} / \mathrm{ml})$ at $4{ }^{\circ} \mathrm{C}$. The slices were washed three times with PBS and confocal microscope (Nikon, Tokyo, Japan) studies.

\section{Mouse brain homogenate}

In separate mouse groups, after sacrifice, the mouse brain was taken out from the skull and mixed with protein extraction buffer which was made up of Protein lysate (Applygen, Beijing, China) and a protease inhibitor cocktail (EASYpack, Roche, Basel, Switzerland). The brain was then homogenized by high-speed tissue grinder (Servicebio, Beijing, China), and centrifuged with $12,000 \mathrm{~g}$ at $4{ }^{\circ} \mathrm{C}$ for $10 \mathrm{~min}$. The resulting supernatant was transferred to a new microcentrifuge tube and the protein concentrations were determined using a BCA protein assay kit following the manufacturer's instructions.

\section{Enzyme-linked immunosorbent assay (ELISA)}

The concentrations of $A \beta_{1-40}$ and $A \beta_{1-42}$ were determined by ELISA kits of $A \beta_{1-40}$ (KHB344) and $A \beta_{1-42}$ (KHB3481) (Invitrogen, California, USA). Tissues were treated with TBS and $5 \mathrm{M}$ guanidine/50 mM Tris HCL ( $\mathrm{pH} 8.0$ ) buffer before $A \beta_{1-40}$ and $A \beta_{1-42}$ ELISA measurement [32]. Changes in inflammatory cytokines (IL-1 $\beta$, IL-6, TNF $\alpha$ ) in the brain were detected by ELISA kits of IL-1 $\beta$ (SEA563MU), IL-6 (SEA079MU), TNF $\alpha$ (SEA133MU) (Cloud-Clone, TX, USA). All the ELISA kits were used in accordance with the manufacturer's instructions ( $n=6$ per group).

\section{Western blotting}

The hippocampus was dissected from mice brains and total protein was extracted. Equal amount of protein (20 $\mu \mathrm{g})$ was denatured for $10 \mathrm{~min}$ in loading buffer at $95{ }^{\circ} \mathrm{C}$, separated by $10-15 \%$ sodium dodecyl sulfate polyacrylamide gel electrophoresis (SDS-PAGE), and transferred to PVDF membrane (Bio-Rad, CA, USA) for $2 \mathrm{~h}$ at $4{ }^{\circ} \mathrm{C}$. Membranes were blocked in 5\% skim milk powder in TBS-T (TBS plus $0.1 \%$ Tween-20) for $1 \mathrm{~h}$ at room temperature. The membrane was then incubated with primary antibodies -- APP (1:1000), the components of the $\gamma$-secretase complex presenilin1 (PS1) (1:1000), beta-site APP-cleaving enzyme 1 (BACE1) (1:1000), NeurofilamentL (1:1000), A $\beta$ (1:1000) (Cell Signaling Technology, MA, USA), a disintegrin and metalloprotease 10 (ADAM10) (1:1000) (Abcam, Cambridgeshire, UK), low-density lipoprotein receptor-related protein 1 (LRP1) (1:1000) (Cell Signaling Technology, MA, USA), Tau (1:1000) (Cell Signaling Technology, MA, USA), Tau-pS396 (1:1000) (Cell Signaling Technology, MA, USA), $\beta$-actin (1:10000) (Sigma-Aldrich, MO, USA) overnight at $4{ }^{\circ} \mathrm{C}$. Followed by incubation with HRP-conjugated goat-anti-mouse or goat-anti-rabbit antibodies (1:10,000, Bio-Rad, CA, USA) for $1 \mathrm{~h}$ at room temperature, the membrane was detected using the ECL reagent (Bio-Rad, CA, USA). The band density was analyzed by Image J software ( $n=6$ per group).

\section{Microarray}

A mouse genome 70-mer oligonucleotide microarray ( $n=3$ per group) was obtained from CapitalBio 
Corporation (Beijing, China) [33, 34]. RNA extraction, amplification, labeling, and hybridization microarray imaging and data analysis were performed according to the manufacturer's instructions (CapitalBio Corp., Beijing, China). Statistical method $t$ test BenjaminiHochberg false discovery rate $[\mathrm{BH}-\mathrm{FDR}]<0.05,2$-fold change were used to screen out the significantly up- and downregulated genes after IHT. Gene Ontology (GO) Term annotation and Kyoto Encyclopedia of Genes and Genomes (KEGG) signaling pathway were used to analyze the function of altered genes.

\section{Quantitative real-time PCR}

Total RNA was isolated from the three samples used in the microarray analysis, using TRIzol reagent according to the manufacturer's instructions (Invitrogen, Carlsbad, CA, USA). Reverse transcription was performed by a reverse transcription kit (Vazyme Biotech Company Limited, China). cDNA was amplified by real-time PCR using SYBR Green master mix (Vazyme Biotech Company Limited, China) as recommended by the manufacturer. Gene expression was calculated relative to $\beta$-actin. Oligonucleotide primer sequences were listed in Table 1.

\section{Data analysis}

All data are presented as means \pm the standard error of the mean (SEM). Unpaired $T$ test was used to compare data between the control and IHT groups respectively. The level of statistical significance was set at $p<0.05$. All graphs were generated using GraphPad 8.0 software.

\section{Results}

IHT alleviates cognitive impairment in 6-month-old APP/ PS1 mice

IHT for 14 days or 28 days

Six-month-old APP/PS1 transgenic male mice were subjected to intermittent hypoxia $\left(14.4 \% \mathrm{O}_{2}\right.$, altitudes of
$3000 \mathrm{~m}, 4 \mathrm{~h} /$ day) for 14 days or 28 days and then behavioral tests were performed (Fig. 1a). Wild type 6-monthold male C57/BL6J mice treated with the same IHT regime as the APP/PS1 showed no significant difference in the escape latency $(p=0.5243)$, the time to the first entry to the platform $(p=0.6746)$, the number of cross over the platform location $(p=0.9043)$, time spent ( $p=$ $0.6831)$, the distance traveled $(p=0.2319)$, and the mean velocity $(p=0.2684)$ in the goal quadrant compared to the control group mice (Additional file 1: Fig. S1, a to f). The results implied that IHT did not significantly affect the learning and spatial memory of the wild-type mice. IHT APP/PS1 mice showed a shorter latency to find the platform compared with APP/PS1 mice without IHT at day 5 (IHT 14 days: $p=0.0219$; IHT 28 days: $p=0.0179$ ) (Fig. 1b). APP/PS1 mice with IHT spent a significantly shorter time in first entry the platform compared with APP/PS1 mice without IHT (IHT 14 days: $p=0.0092$; IHT 28 days: $p=0.0069$ ) (Fig. 1c). APP/PS1 mice with IHT had significantly more crossing platform times in the probe trial at different time point compared with the mice without IHT (IHT 14 days: $p=0.0351$; IHT 28 days: $p=0.0139$ ) (Fig. 1d). Furthermore, APP/PS1 mice with IHT spent significantly longer time (IHT 14 days: $p$ $=0.0332$; IHT 28 days: $p=0.0396$ ) and longer distance (IHT 14 days: $p=0.0429$; IHT 28 days: $p=0.0489$ ) in goal quadrant compared with normoxic mice (Fig. 1e, f). The results suggested that mice in the IHT group focused on looking for the platform in the goal quadrant.

The IHT did not significantly change the mean velocity (IHT 14 days: $p=0.2700$; IHT 28 days: $p=$ 0.6588) (Fig. 1g), the heart rate, breath rate, DBP, SBP, $\mathrm{MBP}, \mathrm{PO}_{2}$, except the body weights which were significantly reduced by IHT 14 days and 28 days (Additional file 1: Table S1). Routine blood test was examined after IHT 14 days, and we found IHT increased hematocrit $(\mathrm{HCT})(p=0.0236)$ and hemoglobin (HGB) levels $(p=0.0116)$ (Additional file 1: Fig. S2, a to b),

Table 1 QPCR primer sequences

\begin{tabular}{|c|c|c|}
\hline Genes & Forward & Reverse \\
\hline APP & 5'-CCTTCTCGTTCCTGACAAGTGC-3' & 5'-GGCAGCAACATGCCGTAGTCAT-3' \\
\hline Bace1 & 5'-TGCTGCCATCACTGAATCGGAC-3' & 5'-GGAATGTGGGTCTGCTTCACCA-3' \\
\hline PS1 & 5'-GCAGTATCCTCGCTGGTGAAGA-3' & 5'-CAGGCTATGGTTGTGTTCCAGTC-3' \\
\hline Cdk5 & 5'-GTACTCCACGTCCATCGACATG-3' & 5'-GCCATTGTTCCTCAGTCGGTGT-3' \\
\hline Cdk5r1 & 5'-TCATCTCGGTGCTGCCTTGGAA-3' & 5'-TTGGCACAGGACAGCGACTTCT-3' \\
\hline Csnk1a1 & 5'-GATGTCCACTCCTGTTGAGGTG-3' & 5'-AAGGATGCGGAATAGCTGCCTC-3' \\
\hline Csnk18 & 5'-CCATCAACACGCACCTTGGCAT-3' & 5'-CATACTTCTGCCTCTTGGTGGC-3' \\
\hline Capn1 & 5'-CCTTGTTCAGCAAGTTGGCAGG-3' & 5'-TCCAGGCTGAAGCCATTAGTGC-3' \\
\hline$\beta$-actin & 5'-ACTGTCGAGTCGCGTCCA-3' & 5'-GTCATCCATGGCGAACTGGT-3' \\
\hline
\end{tabular}

APP amyloid precursor protein, Bace 1 beta-site APP-cleaving enzyme 1, PS1 presenilin1, Cdk5 cyclin-dependent kinase 5, Cdk5r1 cyclin-dependent kinase 5 regulatory subunit 1, Csnk1a1 casein kinase 1 alpha1, Csnk1 $\delta$ casein kinase 1 delta, Capn 1 calpain 1 


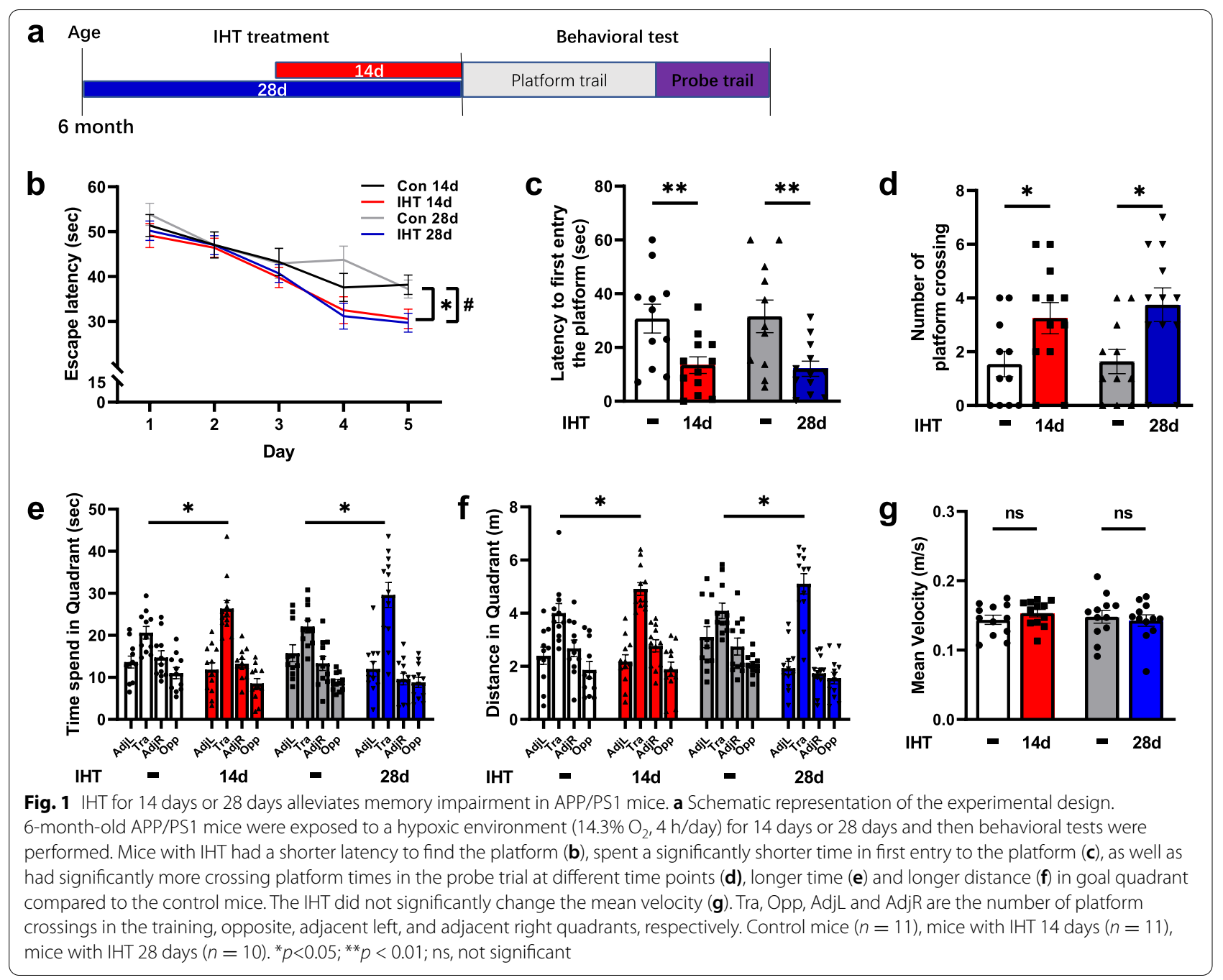

but did not significantly effect in the number of white blood cell (WBC) $(p=0.3911)$, red blood cell (RBC) $(p$ $=0.4898)$, neutrophil $(p=0.5354)$, and platelet $(p=$ 0.5053) (Additional file 1: Fig. S2, c to f). Both 14 days and 28 days of IHT significantly improved memory in 6-month-old APP/PS1 mice; however, there was no differences in behavior test (latency to first entry the platform: $p=0.7531$, crossing platform times: $p=0.5646$, time in goal quadrant: $p=0.3677$, distance in goal quadrant: $p=0.6731$, the mean velocity: $p=0.2852$ ) between the two groups. Hence, the 14 days IHT was used only in the subsequent experiments.

\section{IHT for 14 days with intervals of 14 days or 42 days}

To explore how long the memory improvement by IHT lasted, we next performed the behavior tests after 14 days IHT following different interval times (14 days or 42 days) in 6-month-old APP/PS1 mice (Fig. 2a). For the mice having 14 days IHT with 14 days of interval, the escape latency of the IHT group was significantly shorter compared to the control at day $5(p=0.0481)$ (Fig. 2b). Mice in IHT group spent a significantly shorter time in first entry the platform ( $p=0.0086$ ) (Fig. 2c), and longer time spent in the goal quadrant $(p=0.0187)$ (Fig. 2e). We observed no significant difference in the number of cross over the platform location $(p=0.0760)$ (Fig. 2d) and distance traveled ( $p=0.0759$ ) (Fig. 2f) between the control and 14 days IHT with 14-day interval mice. For the mice treated with 14 days IHT with 42 days of interval, we observed no significant difference in the escape latency ( $p=0.0481)$ (Fig. 2b), in the time to first entry the platform $(p=0.5606)$ (Fig. 2c), number of cross over the platform location $(p=0.06497)$ (Fig $2 \mathrm{~d}$ ), and time spent $(p=0.2128)$ (Fig. 2e) and distance traveled ( $p=$ 0.3603) (Fig. 2f) in the goal quadrant compared to the control group mice. Similarly, IHT does not affect the 


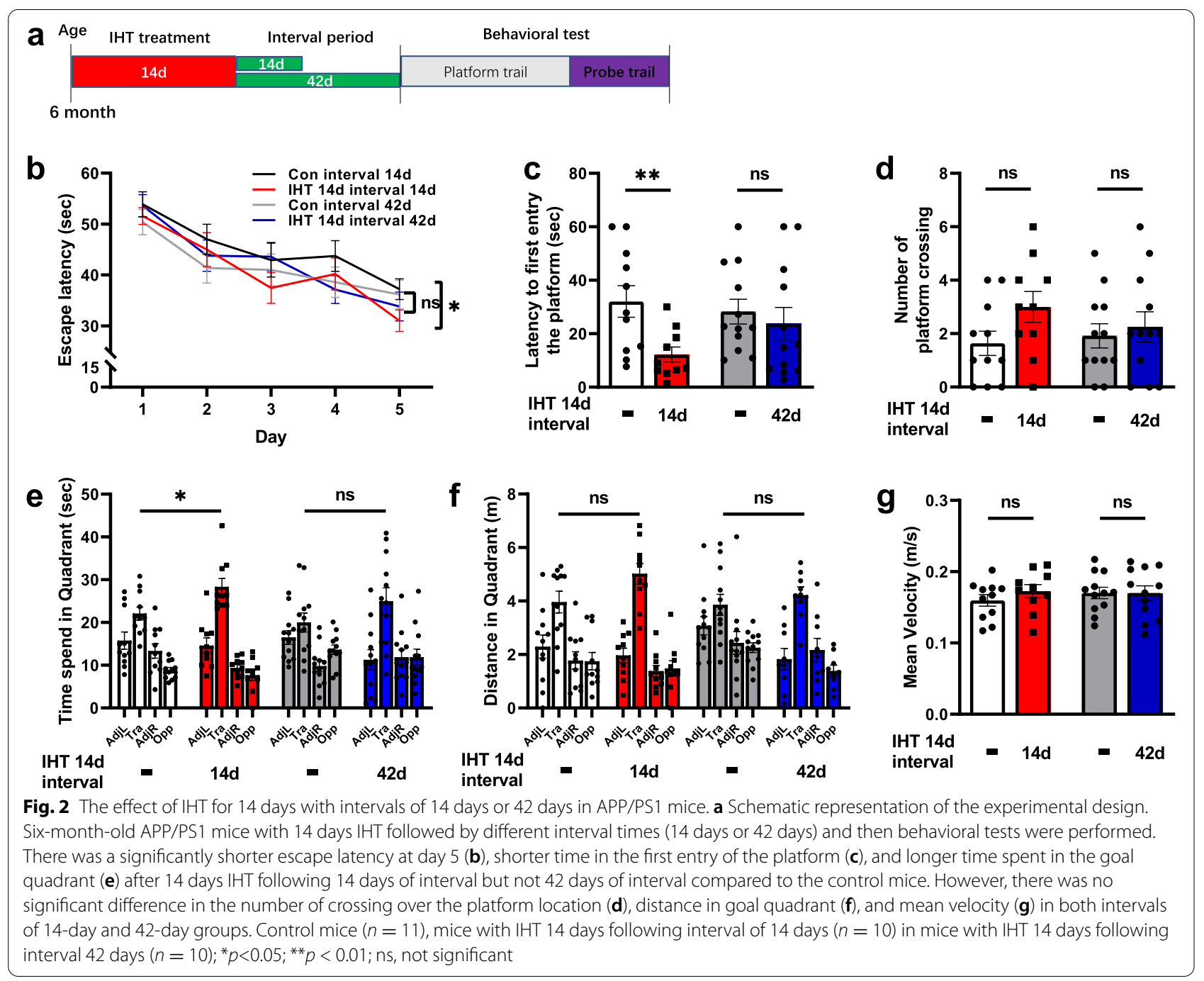

mean velocity (interval of 14 days: $p=0.3054$; interval of 42 days: $p=0.9411$ ) (Fig.2g). This suggests that the memory improvement by 14 days IHT lasts to 14 days, but not to 42 days.

\section{IHT in 6-month-old APP/PS1 mice reduces amyloid load and inflammatory response}

Compared to the control mice, the APP/PS1 mice having 14 days IHT significantly decreased the number of $A \beta$ immunoreactive plaques in the hippocampus (Fig. 3b), but not in the cortex (Fig. 3a). Quantification showed that APP/PS1 mice were subjected to IHT for 14 days significantly reduced plaque number by approximately $31 \%$ $(p=0.0012)$ in the hippocampus (Fig. 3g). While there was no significant change in plaque number $(p=0.8094)$ in the cortex (Fig. 3e). The beneficial effect of IHT on AD pathogenesis was further confirmed by counting the area of plaques in brain sections by image J analyses. The area of plaques in APP/PS1 mice were significantly decreased after 14 days IHT (cortex: $p=0.0104$; hippocampus: $p=$ 0.0026) (Fig. 3f, h).

We next examined the microglial reactivity in mouse brains using IBA1 and the neurofilament accumulations. IHT (14 days) APP/PS1 mice significantly decreased the accumulates area formed by neurofilament accumulations and IBA1 positive cells aggregation (Fig. 3c, d). Quantification showed that the accumulates area was reduced by nearly $20 \%$ (neurofilament accumulations: $p=0.0346$; IBA1: $p=0.0122$ ) in IHT group (Fig. 3i, j). There was no significant difference in lectin staining (p $=0.1993$ ) (Additional file 1: Fig. S3). Lectins, which bind with high affinity to specific $\mathrm{N}$-acetyl-D-glucosamine and poly-N-acetyl lactosamine sugar residues of endothelial plasma membrane glycocalyx, are commonly used 


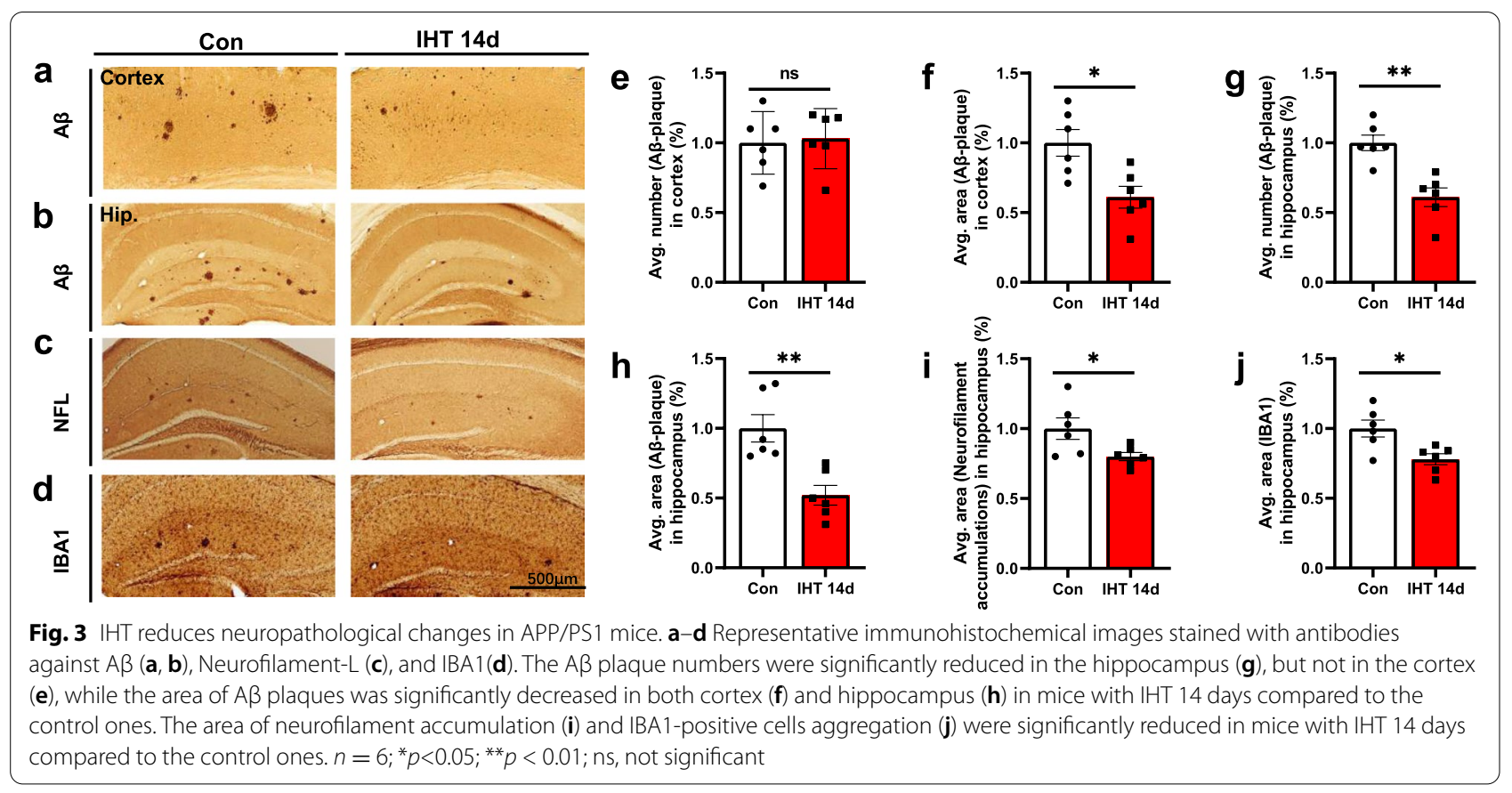

markers for studying the endothelial cells [35]. In our study, there was no significant difference in vascular density in the APP/PS1 mouse brain between the IHT 14 days and the control groups, this suggested that IHT may have no significant effect on vascular structure.

Then, we performed ELISA to analyze the levels of $\mathrm{A} \beta_{1-40}$ and $A \beta_{1-42}$ in the hippocampus in mice with IHT 14 days. The levels of $A \beta_{1-40}$ and $A \beta_{1-42}$ were reduced to $75.96 \pm 4.4 \%$ and $70.08 \pm 7.52 \%$ respectively compared to controls $\left(\mathrm{A} \beta_{1-40}: p=0.0135 ; \mathrm{A} \beta_{1-42}: p=0.0107\right)$ (Fig. 4a, $\mathrm{b})$. These data indicate that IHT reduces the formation of plaques and $\mathrm{A} \beta$ production in the $\mathrm{AD}$ mice. We then examined changes in the pro-inflammatory cytokines IL-1 $\beta$, IL- 6 , and TNF- $\alpha$ after exposure to IHT for 14 days. The result indicated that IHT down-regulated the level of IL-6 ( $p=0.0125)$ (Fig. $4 \mathrm{c})$ and IL-1 $\beta$ ( $p=$ 0.0110 ) (Fig. 4d) but did not affect the level of TNF- $\alpha$ ( $p$ $=0.0919)($ Fig. 4e) in the brain tissue. These results demonstrate that IHT reduces the inflammatory response. In our study, 14 days IHT reduces the plaque load and inflammatory in APP/PS1 mice, but we did not observe the effect on the plaque load and inflammatory with an interval of 14 days.

We next analyzed molecules related to the degradation of APP via Western blotting. The expression of APP ( $p=$ $0.0775), \operatorname{PS} 1(p=0.0751)$, and $\alpha$-Synuclein $(p=0.1166)$ (Fig. 5b, f, g) in brain tissue was not significant difference after IHT for 14 days, but we observed markedly increased ADAM10 ( $p=0.0011)$ (Fig. 5c) and reduced $\operatorname{BACE} 1(p=0.0018)$ levels (Fig. 5d) in APP/PS1 mice with
IHT 14 days, while the expression of Neurofilament- $\mathrm{L}(p$ $=0.0011)$ (Fig. 5e) and $\mathrm{A} \beta(p=0.001)$ both down-regulated. We also measured Tau and LRP1 protein levels, and found Tau-pS396 was reduced after IHT (IHT 14 days: $p=0.0093$, IHT 28 days: $p=0.0205$ ) (Additional file 1: Fig. S4) but there was no statistical difference of LRP1 level between two groups $(p=0.1458)$ (Additional file 1: Fig. S5). Taken together, these results demonstrate that IHT inhibits amyloidogenic APP processing.

\section{Microarray analysis of gene expression in APP/PS1 mice after IHT}

To determine the gene expression profile in the hippocampus of APP/PS1 mouse after IHT, we performed microarray analysis representing 6,347 genes. Generally, there were 261 genes that were significantly up- and downregulated after IHT ( $t$ test BH FDR $<0.05,2$-fold change). GO term annotation and KEGG signaling pathway were used to analyze the function of altered genes. The results showed that the most significant genes were mainly associated with energy derivation by oxidation of organic compounds, regulation of GTPase activity, and some metabolic processes at the biological process level (Fig. 6a). Among the top, the changed number of genes in GO annotations after IHT were "metabolic process," "cellular process," and "biological regulation" (Additional file 1: Table S2). In addition to annotation the function of genes, genes are involved in various pathways. The most significant pathways of enriched genes were ribosome, oxidative phosphorylation, and some neurodegenerative 

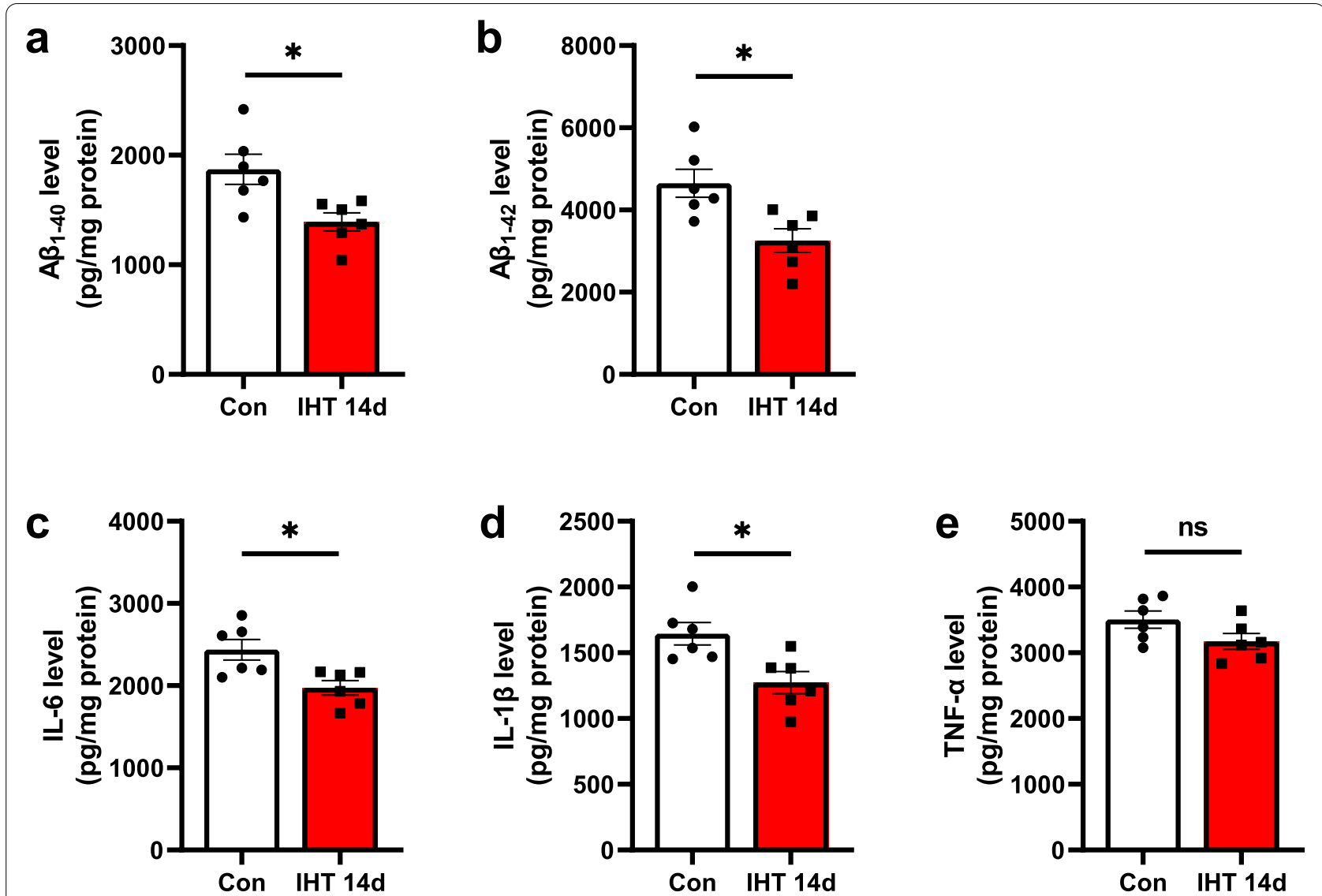

Fig. $4 \mathrm{HT}$ decreases the levels of $A \beta_{1-40}\left(A \beta_{1-42}\right)$ and the pro-inflammatory cytokines in the brain of APP/PS1 mice. Mice with IHT 14 days had reduced levels of $A \beta_{1-40}(\mathbf{a})$ and $A \beta_{1-42}(\mathbf{b})$, IL-6 (c), and IL-1 $\beta(\mathbf{d})$ in the brain compared to the control mice. However, the level of TNF- $\alpha$ was not changed by the IHT (e). $n=6 ;{ }^{*} p<0.05 ;$ ns, not significant

diseases involved AD (Fig. 6b). Besides, the pathways with more enriched genes were Glycolysis/Gluconeogenesis and Citrate cycle (TCA cycle) (Additional file 1: Table S3). In general, the large numbers of genes with significantly altered in IHT APP/PS1 mice are known to be metabolism-regulated genes.

Glycogen synthase kinase 3 beta (Gsk-3 $\beta$ ) and cyclindependent kinase $5(\mathrm{Cdk} 5)$ are key molecules in the development of $\mathrm{AD}[36,37]$. GSK-3 3 , a major Tau kinase, has been found to be overactivated in the brains of $\mathrm{AD}$ patients $[38,39]$, it is responsible for the hyperphosphorylation of tau, which is an important component of NFTs, making it play a key role in the pathogenesis of $\mathrm{AD}$ [40]. GSK-3 $\beta$ is also involved in A $\beta$-induced toxicity through different mechanisms, it has been reported that A $\beta$ blocks Wnt-mediated GSK-3 $\beta$-inhibition leading to an increase in $A \beta$ formation and tau hyperphosphorylation [41]. Further, GSK-3 $\beta$ is expressed in both microglia and astrocytes, as a modulator of inflammatory cytokine levels in the brain, promotes the production of cytokines [42]. A surprising result from the microarray study was that the expressions of several key genes involved in the regulation of $\mathrm{AD}$ pathology include the genes encoding microtubule-associated protein (Tau), the components of the $\gamma$-secretase complex PS1, Gsk-3 $\beta$, protein phosphatase 2 (Ppp2ca), Cdk5, Cdk5r1, Capn1, Csnk1 1 1, and Csnk1 $\delta$ decreased.

Quantitative PCR was performed to validate the altered expression levels of these genes using cDNA derived from total RNA of the brain tissue samples. There was a good agreement between the microarray and Q-PCR results (Fig. $6 \mathrm{c}-\mathrm{j})$. Relative quantitative analysis of gene expression was performed: APP ( $p=0.6489)$ (Fig. 6c), Bace1 ( $p$ $=0.0013)$ (Fig. 6d), PS1 $(p=0.0490)$ (Fig. 6e), Cdk5 ( $p=$ 0.0129) (Fig. 6f), Cdk5r1 ( $p=0.0043)$ (Fig. 6g), Csnk1 1 $(p=0.0125)$ (Fig. 6h), Csnk1 $(p=0.0066)$ (Fig. 6i), and Capn1 ( $p=0.0016)$ (Fig. 6j). Consistently, the protective role of IHT on APP/PS1 mice probably acts on APP processing and decreases $A \beta$ production by inhibiting the GSK3 $\beta$ pathway.

Interestingly, most of the genes from our signature that are down-regulated after IHT such as Capn1, Csnk1 $\delta$, 


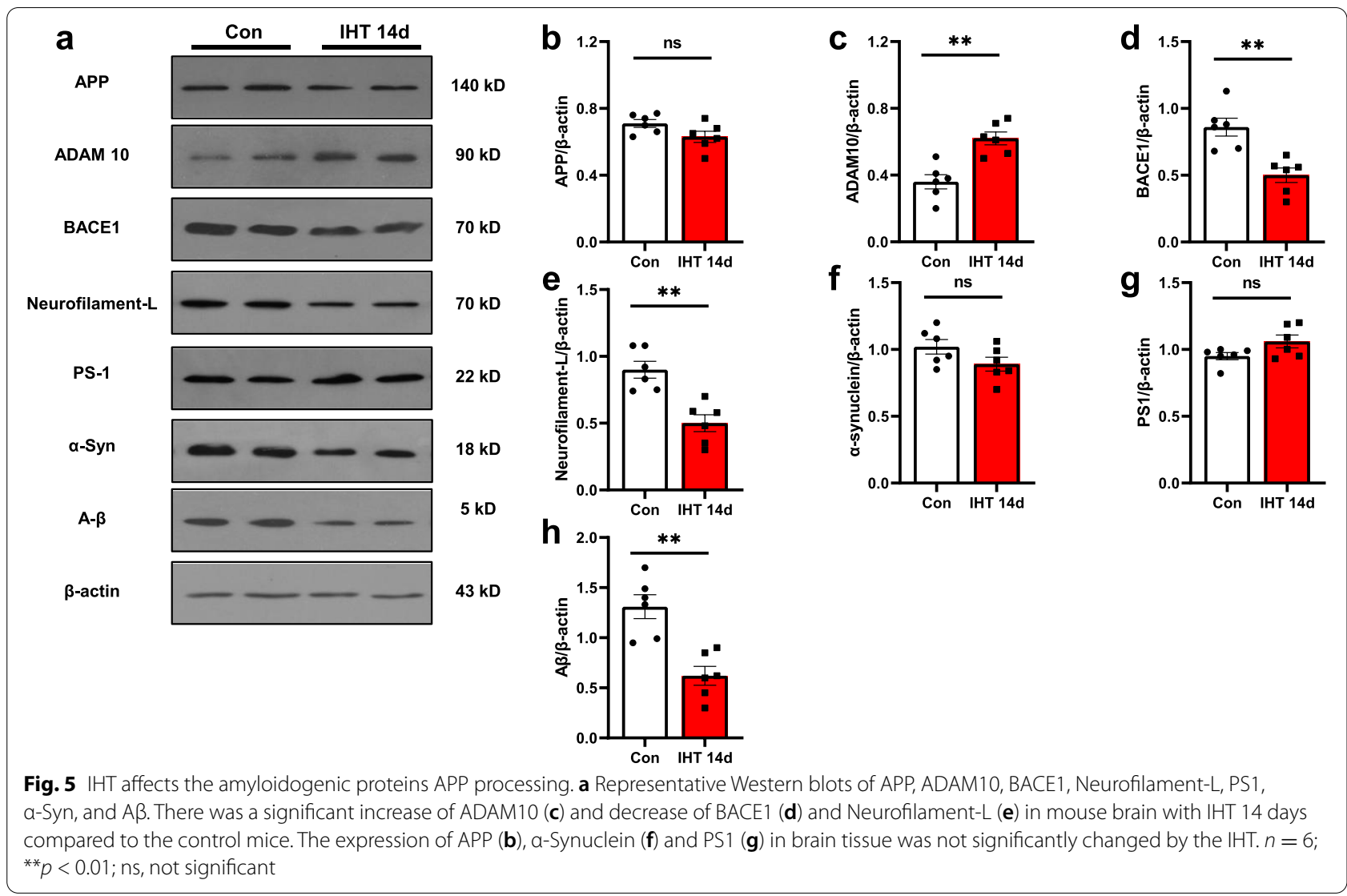

Csnk1 $\alpha 1$, Cdk5, and Cdk5r1, belong to p53 related pathway. Increasing evidence has suggested p53 pathway plays a pivotal role in $\mathrm{AD}$, implying that modulation of cell death pathways might be of therapeutic benefit in IHT and indeed in age-related neurological disorders.

\section{Discussion}

In this study, we provided evidence of the beneficial effect of IHT on the APP/PS1 mice as shown in the working model (Fig. 7). We demonstrated that 14 days IHT inhibited $A \beta$ production, reduced neuritic plaque formation, and alleviated the memory deficits in 6-month-old APP/ PS1 mice, suggesting that IHT could be used for the prevention/treatment of $A D$. We further showed IHT alleviated $A D$ pathogenesis by reducing $\beta$-secretase cleavage of APP processing thus decreasing $A \beta$ production in the brain tissue. In addition, we found a large number of genes expression were significantly altered by IHT, most of which were known to be metabolism-regulated genes or be enriched in p53 pathway, implying that modulation of metabolism and cell death by IHT might be of therapeutic benefit in AD.

$\mathrm{AD}$ is a progressive neurodegenerative disease characterized by cognitive decline and behavioral changes [43].
Formation of amyloid plaques and NFTs are two central hallmarks in the AD. Amyloid plaques are the dense composites of $A \beta$ which accumulates around the nerve cells, while NFTs are the twisted fibers containing hyperphosphorylated tau proteins present in certain residues of $\mathrm{A} \beta$ that build up inside the brain cells $[44,45]$. The epitope defined by phosphorylation of S396 in tau protein is strongly implicated in $\mathrm{AD}$-associated tau pathology [46]. We found IHT could reduce Tau-pS396 protein levels and NFTs density in the APP/PS1 mice. High levels of fibrillary $A \beta$ in the brain are associated with neuronal and synaptic loss and impairment of neuronal functions [47]. $A \beta$ is a cleaved product of the APP via proteolysis by BACE1 and $\gamma$-secretase [48]. BACE1 is a prime drug target for slowing down $A \beta$ production in early $A D$ [49]. In $A D$, excessive accumulation of $A \beta$ monomers results in their assembly into soluble, diffusible oligomers e.g. $A \beta$ dimers which directly induce tau hyperphosphorylation and neurite degeneration [50]. In this study, we found IHT could reduce BACE1 while increasing $\alpha$-secretase levels resulting in reduced $A \beta$ plaque and deposition in 6-month-old APP/PS1 mice. This is consistent with a number of studies that demonstrate cognitive improvement following inhibition of $A \beta$ generating enzymes in 


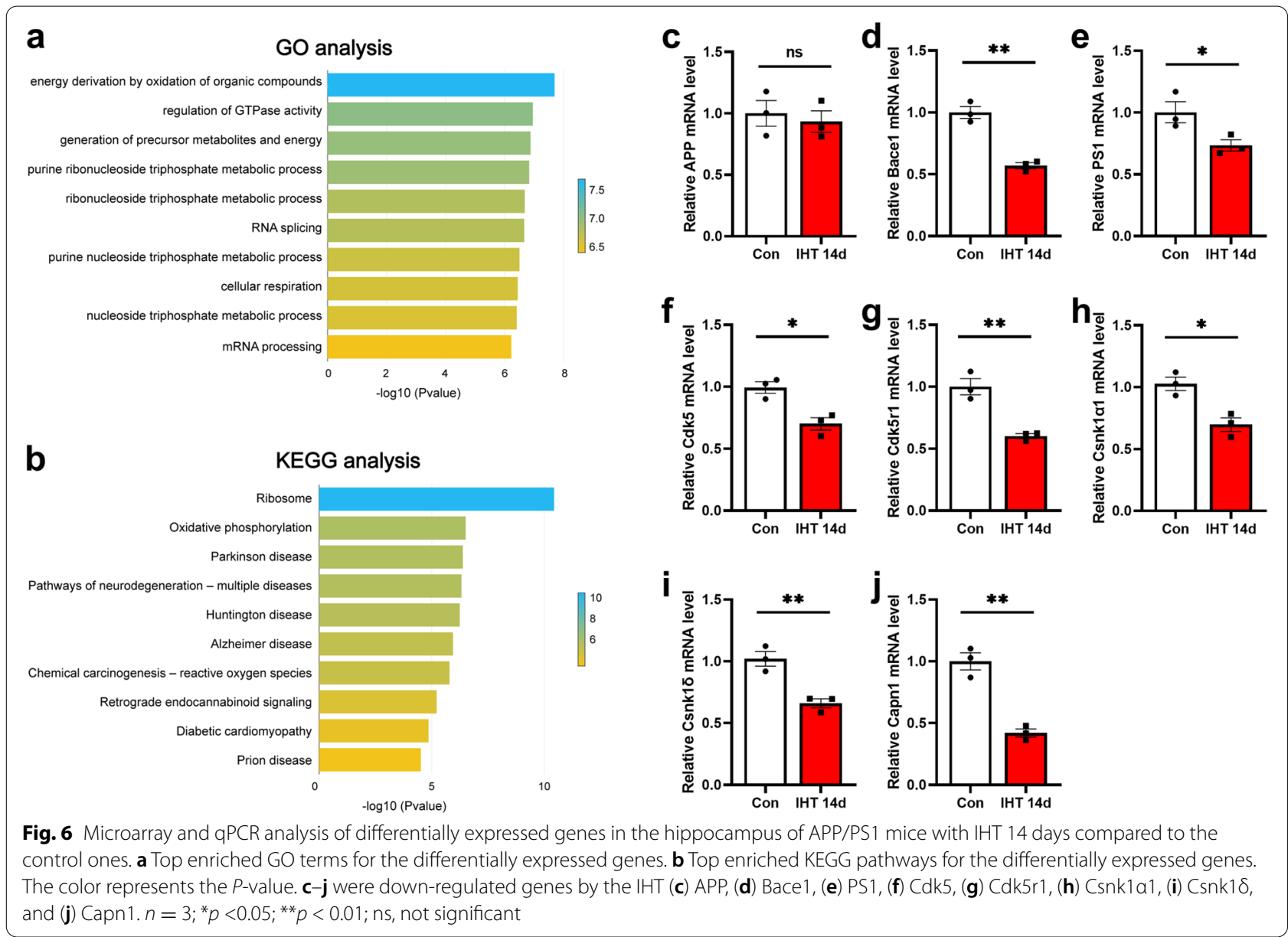

mouse models of AD [51, 52]. LRP1 is highly expressed by neurons and has multiple functions in the regulation of cerebrovascular homeostasis and AD' pathology. Many evidences have indicated that LRP1 mediates brain $A \beta$ clearance and amyloid deposition [53-56], but in the present study, IHT did not significantly affect LRP1 protein expression.

It has been demonstrated that there are increased amyloid brain levels in APP/PS1 mice since 3 months old while strong plaque deposition can be detected at 6 months [57-59]. The previous studies from our and other groups have identified that $A \beta$ aggregation was correlated with memory deficits in the APP/PS1 mice [60-62]. Consistent with this finding, we found 14 days of IHT significantly reduced $A \beta$ protein expression and A $\beta$ aggregation, improved the cognitive performance in APP/PS1 mice. The results indicated that IHT may serve as a protective role of $A \beta$-induced $A D$ pathological processes.

The protein neurofilament-L is a key component of axons and the main byproduct of nerve cell degeneration. Research studies have shown neurofilament accumulations in many human neurological disorders including Parkinson's disease, AD, Charcot-Marie-Tooth disease, and Amyotrophic Lateral Sclerosis [63]. It has been found in both cerebrospinal fluid and blood in $\mathrm{AD}$ patients [64, 65]. Neurofilament-L has been used as a biomarker and may monitor efficacy of disease-altering drugs in clinical trials with AD patients [65-69]. In our study, the expression of neurofilament-L protein was reduced by nearly $45 \%$ after IHT 14 days. IHT was found to promote hippocampal neurogenesis [15], to prevent overproduction of nitric oxide in the brain and neurodegeneration induced by $A \beta$ toxicity [70], and to enhance brain-derived neurotrophic factor (BDNF) expression in 9 months APP/PS1 mice [71].

Neuroinflammation, the inflammatory response of the central nervous system, can be caused as a result of $A \beta$ plaques deposition and contributes to the progression of AD [72-74]. Although neuroinflammation has roles in protecting the brain, prolonged neuroinflammation has been known to increase $A \beta$ burden and the plaque deposition creates a vicious cycle where the $A \beta$ load is increased which further results in microglia activation 


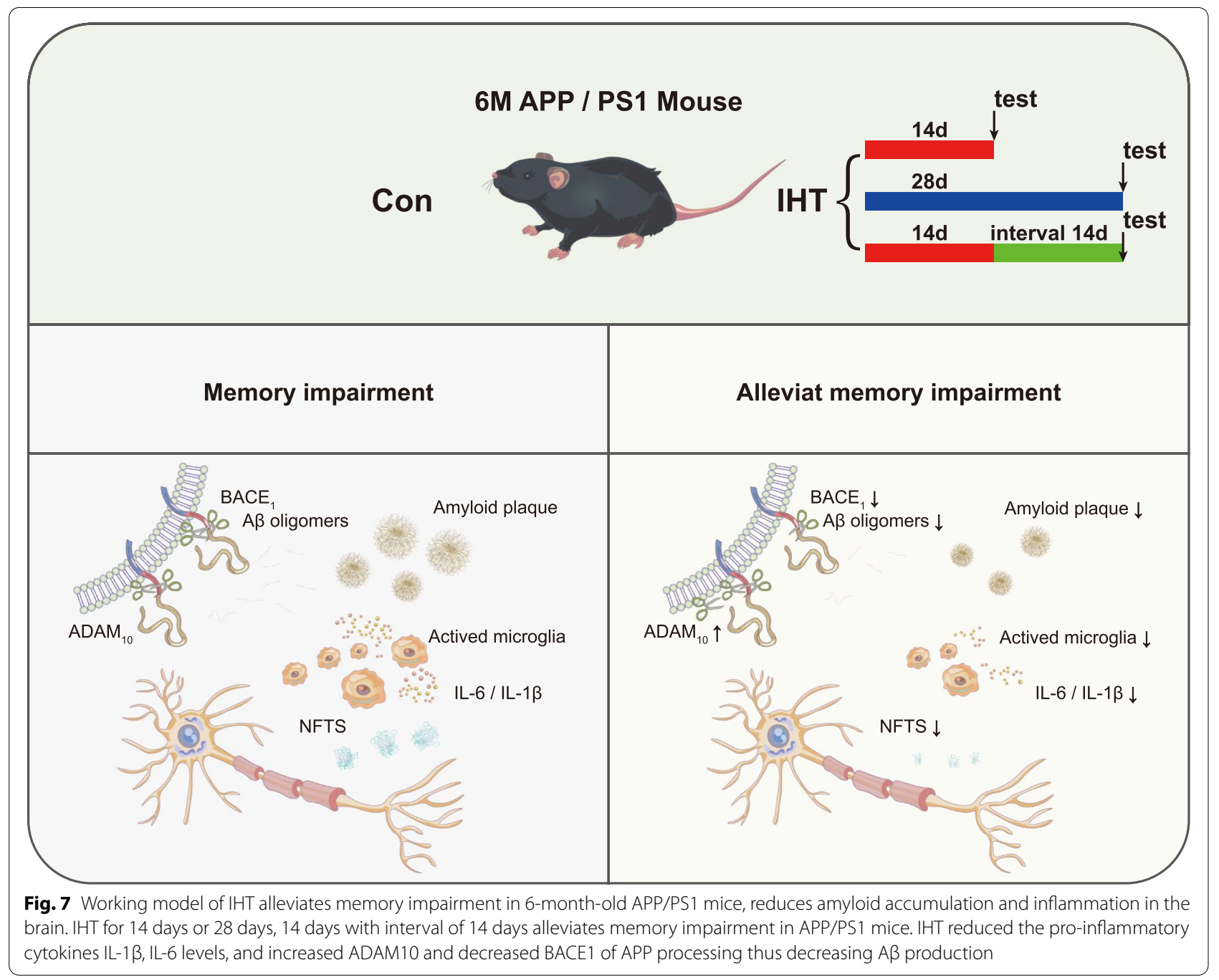

and subsequent neuroinflammation [73]. Increased expression of inflammatory mediators in postmortem brains of people with $\mathrm{AD}$ and epidemiological studies link the use of anti-inflammatory drugs with reduced risk for the disorder [75-80]. Nonsteroidal anti-inflammatory drug treatment can reduce brain $A \beta$ levels, amyloid plaque burden, and microglial activation in an animal model of AD [81]. CD11b-positive microglia and glial fibrillary acidic protein (GFAP) positive astrocytes were first detected at 3 months old APP/PS1 mice with a close association with amyloid plaques [82]. We found IHT (14 days) significantly decreased the area of plaques formed by IBA1 positive cells aggregation in APP/PS1 mice. IBA1 is specifically expressed in macrophages/microglia antibody and the area of plaques formed by IBA1 positive cells aggregation shows the microglial reactivity [83]. The brains of APP/PS1 mice were under an active inflammatory stress, the amplitude of cytokine response TNF$\alpha$, IL-6, and other inflammatory factors was dependent on A $\beta$ levels [84]. IHT reduced the pro-inflammatory cytokines in mice: IL-1 $\beta(p<0.05)$, IL-6 $(p<0.05)$, and TNF- $\alpha(p>0.05)$ in their protein expressions in the brain. These data indicated that the effect of IHT on APP/PS1 mice might be related to an inflammatory response.

Oxygen is vital to maintain the normal functions of almost all the organs [85]. The important roles of oxygen are not only reflected in the development, but also in the pathological processes of many cerebral diseases [16]. Oxygen supply in brain tissue plays a key role in neurodegeneration during the aging process [86]. Previously studies reported that acclimatization to hypoxia when ascent to altitude is reflected by progressive increases in ventilation, adaptations in the cardiovascular system that enhance oxygen delivery to tissues for better extraction of oxygen, and more efficient utilization of oxygen for metabolic processes from the integrative systems to the molecular and genomic level [19]. These adaptive responses raise the potential therapeutic 
possibility of IHT on these neurodegenerative diseases. There is also epidemiological evidence that resistance to altitude may impact the risk of death rates in $\mathrm{AD}$, which each doubling of altitude was associated with a 2 percent reduction in Alzheimer's death rates [87]. A number of studies examined IHT's safety and therapeutic efficacy in elderly patients with mild cognitive impairment $(\mathrm{MCI})$, a precursor symptom of $\mathrm{AD}$. They suggest that adaptation to moderate IHT may enhance cerebral oxygenation, improve cognitive function, and decrease circulating biomarkers of $\mathrm{AD}[88,89]$.

The beneficial effects of IHT to promote memory deficits in the 6-month-old APP/PS1 mice are due in part to its ability to induce changes in gene transcription. We found that the expression of a wide variety of genes involved in IHT on AD pathogenesis is largely due to the regulation of Glycolysis/Gluconeogenesis, TCA cycle, APP processing, and cell death. The most significant pathways of enriched genes were ribosomes. Ribosomes are the cellular factories responsible for making proteins. It is the ribosome that reads the sequence of mRNA and translates it into the correct sequence of amino acids for each protein. Although no data are available regarding the precise mechanism of IHT on neurodegenerative diseases, it provides new directions for neurology aimed at understanding mechanisms of IHT on aged-related diseases. Other mechanisms that could account for the effective roles of IHT need further investigation.

There are several different experimental models to study IHT in animals. The different protocol also has different effects on various diseases mainly depending on the intervals and the altitude of hypoxic exposures, the number of hypoxic episodes per day, and the number of exposure days. Goryacheva et al. demonstrated IHT (4000 $\mathrm{m}$ for 14 days, $4 \mathrm{~h}$ per day) significantly alleviated the memory deficiency in rats with $\mathrm{A} \beta_{25-35}$ being injected into the basal macronuclei of the brain [70]. Suzuki discovered short-duration of IHT ( 4 cycles of $12-13 \% \mathrm{O}_{2}$ for $15 \mathrm{~min}$ and $20.9 \% \mathrm{O}_{2}$ for $10 \mathrm{~min}$ ) for 28 days facilitated endurance exercise performance in mice [90].

On the contrary, Snyder et al. found increased oxidative stress and inflammation in a manner consistent with early stages of neurodegenerative disease in rats were exposed to 7 days chronic intermittent hypoxia for $8 \mathrm{~h} /$ day [91]. Shiota et al. reported that chronic intermittent hypoxia/reoxygenation $\left(5 \% \mathrm{O}_{2}\right.$ and $21 \% \mathrm{O}_{2}$ every $10 \mathrm{~min}$, $8 \mathrm{~h} /$ day for 4 weeks) facilitates amyloid- $\beta$ generation in AD model mice [92].

Recently, more and more studies have shown that some non-invasive stimuli can improve the cognitive behavior and pathological changes of AD mouse models. The methods were different but showed similar positive results. A non-invasive light flicker (gamma entrainment using sensory stimulus or GENUS) furthermore, combined auditory and visual GENUS, have been reported to improve spatial and recognition memory and reduce amyloid in AC and hippocampus of 5XFAD mice [93, 94]. Hyperbaric oxygen therapy (HBOT) attenuated neuroinflammatory processes and reduced amyloid burden, and tau phosphorylation in 3xTg mice, and ameliorated their behavioral deficits [32]. HBOT did the opposite of our study but showed very similar effects in terms of reducing beta amyloid pathology. The reason may be that IHT and HBOT both have wide-ranging effects on the brain to improve cognitive function through different mechanisms [95].

Previous studies of our lab showed that the proliferation of neural stem cells in the hippocampal subventricular zone (SVZ) and dentate gyrus (DG) was significantly increased in adult rats with IHT for 2 weeks at $3000 \mathrm{~m}$ altitude [96]. In vivo real-time oxygen probe detection revealed that oxygen content in the hippocampal DG region fluctuated significantly after IHT, and promote the growth of dendritic spines of hippocampal neurons [17]. IHT promotes neurogenesis leading to more newborn neurons in the hippocampus in adult rats and stably enhanced the expression of BDNF to relieve the depressant-like effects in animal models, suggesting that IHT is involved in BDNF signaling [15]. In contrast, chronic or severe hypoxia significantly alters neurotransmitter systems and produces progressive brain injury and subsequent impairment of neural function $[97,98]$. This may be explained to the adverse effect of different episodic hypoxia to differentiate between physiological and pathological responses in neurodegenerative diseases.

\section{Limitations}

This study has several limitations as follows: (i) it is well established that inflammation and hypoxia-induced pathways are different between sex, while we used only male $\mathrm{AD}$ mice in this study for reducing variants in the experiments. It remains to be studied whether IHT has similar effects on female APPswe/PS1dE9 mice; (ii). considering the timeliness of IHT, we only adopted the water maze to test the spatial learning and memory ability of mice. The results will be more solid if other behavioral tests can be used without affecting the timeliness of IHT, for example, the Y-maze test and novel object location etc.; (iii). hypoxia is a double-edged sword, severe and persistent hypoxia can cause damage to the body, while mild and temporary hypoxia can bring beneficial effects to the body. Our study represents a proof of concept; however, the duration of IHT can be further optimized; (iv). since $\mathrm{AD}$ is a chronic neurodegenerative disease, further studies are needed for validating these discoveries in the clinical setting. 


\section{Conclusion}

In conclusion, this study demonstrates that IHT (14 days and 28 days) improves spatial memory ability in 6-month-old APP/PS1 mice. The improvement in spatial memory ability lasts to 14 days but not 42 days of inter$\mathrm{val}$, indicating the beneficial effect of IHT is temporary. The spatial memory ability improvement by IHT is associated with reduced formation of amyloid plaques and neurofibrillary tangles, as well as inhibition of neuroinflammation, and changes in gene expression in the hippocampus. The genes that are down-regulated after IHT such as Capn1, Csnk18, Csnk1 $\alpha 1$, Cdk5, and Cdk5r1, belong to p53 related pathway, suggesting the p53 pathway plays a pivotal role in the process. Our study has further clarified the therapeutic effect of IHT on APP/PS1 mice, and explored the multi-target regulation mechanism of its intervention effect. Although further research is needed to elucidate the underlying beneficial mechanisms of IHT, we suggest that IHT presents a new means for treating $\mathrm{AD}$.

\begin{abstract}
Abbreviations
AD: Alzheimer's disease; IHT: Intermittent hypoxic treatment; APP/PS1: APPswe/PS1-dE9; Aß: Amyloid beta; NFTs: Neurofibrillary tangles; DBP: Diastolic blood pressure; SBP: Systolic blood pressure; MBP: Mean blood pressure; $\mathrm{PO}_{2}$ : Partial pressure of oxygen; IBA1: lonized calcium-binding adaptor molecule 1; DAB: Diaminobenzidine; O.C.T. compound: Optimal cutting temperature compound; APP: Amyloid precursor protein; SDS-PAGE: Sodium dodecyl sulfate polyacrylamide gel electrophoresis; PS1: Presenilin1; BACE1: Beta-site APP-cleaving enzyme 1; ADAM10: A disintegrin and metalloprotease 10; LRP1: Low-density lipoprotein receptor-related protein 1; Cdk5: Cyclin-dependent kinase 5; Cdk5r1: Cyclin-dependent kinase 5 regulatory subunit 1; Csnk1a1: Casein kinase 1 alpha1; Csnk18: Casein kinase 1 delta; Capn1: Calpain1; TCA cycle: Citrate cycle; Gsk-3B: Glycogen synthase kinase 3 beta; Ppp2ca: Protein phosphatase 2; BDNF: Brain-derived neurotrophic factor; GFAP: Glial fibrillary acidic protein; $\mathrm{MCl}$ : Mild cognitive impairment; HBOT: Hyperbaric oxygen therapy; SVZ: Subventricular zone; DG: Dentate gyrus.
\end{abstract}

\section{Supplementary Information}

The online version contains supplementary material available at https://doi. org/10.1186/s13195-021-00935-z.

Additional file 1: Table S1. The physiological parameters in IHT APP/PS1 mice. Table S2. List of GO terms that were significantly affected by IHT in APP/PS1 mice. Table S3. List of KEGG pathway that were significantly affected by IHT in APP/PS1 mice. Figure S1. Effects of IHT on the behavior of wild-type C57/BL6J mice. There was no significant difference in the escape latency (a), the time to first entry the platform (b), number of cross over the platform location (c), time spent (d), the distance traveled (e) and the mean velocity ( $f$ ) in the goal quadrant in C57/BL6J mice with IHT 14d compared to the control group mice. $n=12$ per group. ns, not significant. Figure S2. Effect of IHT on the blood test in APP/PS1 mice. There was no significant difference in (a) HCT: hematocrit, (b) HGB: hemoglobin, (c) WBC white blood cell, (d) RBC: red blood cell, (e) Neutrophil, (f) Platelet in the blood of APP/PS1 mice with IHT 14d compared to the controls. $n=5$ per group. ns, not significant. Figure S3. Representative immunohistochemical images stained with Lectin in APP/PS1 mouse brain sections. There was no significant difference in vascular density in the APP/PS1 mouse brain between the IHT 14d and the control groups. $n=6$ per group. ns, not significant. Figure S4. Representative Western blots of Tau-pS396 and total Tau in mouse hippocampus homogenate. There was significant decrease of the ratios of Tau-pS396 / total Tau protein expression level in APP/PS1 mouse brain between IHT 14d and 28d compared to the control groups. $n=4$ per group; ${ }^{*} p<0.05 ;{ }^{* *} p<0.01$. Figure S5. Representative Western blots of LRP1 in mouse hippocampus homogenate. There was no significant difference of the LRP1 protein expression level in APP/PS1 mouse brain between IHT 14d compared to the control groups. $n=6$ per group. ns, not significant.

\section{Acknowledgements}

We are grateful to Dr. Ming Zhao for the Microarray data analysis, and the members of the Zhenlong Feng, Shaojie Zhang, Yanan Geng, Xuechao Fei for technical assistance.

\section{Authors' contributions}

Lingling Zhu and Ruoli Chen contributed to the conception and design of the work; Xiangpei Yue, Yanzhao Zhou, Meng Qiao, Xingnan Zhao, contributed to data acquisition, analysis, and interpretation. Xiangpei Yue, Ruoli Chen, and Lingling Zhu drafted the work and revised it critically. Tong Zhao, Xiang Cheng, Ming Fan, and Yongqi Zhao contributed data analysis and discussion. All authors have critically reviewed the final draft of the manuscript and given final approval of the version to be published.

\section{Funding}

Beijing Science and Technology Planning Project (No. Z161100000216134), and the National Natural Science Foundation of China (No. 81430044).

Availability of data and materials

The datasets used for the analyses are available from the corresponding author on reasonable request.

\section{Declarations}

Ethics approval and consent to participate

All applicable international, national, and/or institutional guidelines for the care and use of animals were followed.

\section{Consent for publication}

Not applicable.

\section{Competing interests}

The authors declare that they have no competing interests.

\section{Author details}

${ }^{1}$ Beijing Institute of Basic Medical Sciences, Beijing 100850, China. ${ }^{2}$ Institute for Science and Technology in Medicine, School of Pharmacy, Keele University, Kelle, UK. ${ }^{3}$ Co-innovation Center of Neuroregeneration, Nantong University, Nantong 226019, China. ${ }^{4}$ Hengyang Medical School, University of South China, Hengyang 421001, Hunan, China. ${ }^{5}$ Anhui Medical University, Hefei 230022, Anhui, China.

Received: 2 July 2021 Accepted: 9 November 2021

Published online: 29 November 2021

\section{References}

1. Germack R, Leon-Velarde F, Valdes De La Barra R, Farias J, Soto G, Richalet JP. Effect of intermittent hypoxia on cardiovascular function, adrenoceptors and muscarinic receptors in Wistar rats. Exp Physiol. 2002;87(4):453-60.

2. McLean BD, Gore CJ, Kemp J. Application of 'live low-train high' for enhancing normoxic exercise performance in team sport athletes. Sports Med. 2014;44(9):1275-87.

3. Brocherie F, Millet GP, Hauser A, et al. "Live High-Train Low and High" Hypoxic Training Improves Team-Sport Performance. Med Sci Sports Exerc. 2015;47(10):2140-9.

4. Susta D, Dudnik E, Glazachev OS. A programme based on repeated hypoxia-hyperoxia exposure and light exercise enhances performance 
in athletes with overtraining syndrome: a pilot study. Clin Physiol Funct Imaging. 2017;37(3):276-81.

5. Shatilo VB, Korkushko OV, Ischuk VA, Downey HF, Serebrovskaya TV. Effects of intermittent hypoxia training on exercise performance, hemodynamics, and ventilation in healthy senior men. High Alt Med Biol. 2008;9(1):43-52.

6. Tsyganova TN. Comparative efficacy of anemia treatment in mountain health resort and using normobaric intermittent hypoxic training. Vopr Kurortol Fizioter Lech Fiz Kult. 2004:2:41-2.

7. Ustinova EE, Saltykova VA, Didenko VV, Beloshitskiï PV, Meerson FZ. Effects of adaptation to periodic and continuous hypoxia in disorders of electrical stability of the heart in postinfarction cardiosclerosis. Biull Eksp Biol Med. 1988;105(5):533-5.

8. Burtscher M, Gatterer H, Szubski C, Pierantozzi E, Faulhaber M. Effects of interval hypoxia on exercise tolerance: special focus on patients with CAD or COPD. Sleep Breath. 2010;14(3):209-20

9. Syrkin AL, Glazachev OS, Kopylov FY, Dudnik EN, Zagaynaya EE, Tuter DS Adaptation to Intermittent Hypoxia-Hyperoxia in the Rehabilitation of Patients With Ischemic Heart Disease: Exercise Tolerance and Quality of Life. Kardiologiia. 2017:57(5):10-6.

10. Serebrovskaia TV, Man'kovskaia IN, et al. A method for intermittent hypoxic exposures in the combined treatment of bronchial asthma patients. Lik Sprava. 1998;6:104-8.

11. Serebrovskaya TV, Swanson RJ, Kolesnikova EE. Intermittent hypoxia: mechanisms of action and some applications to bronchial asthma treatment. J Physiol Pharmacol. 2003;54(Suppl 1):35-41.

12. IKh B. Intermittent hypoxic training in the sanatorium and spa treatment for patients with chronic obstructive pulmonary disease. Vopr Kurortol Fizioter Lech Fiz Kult. 2007:5:21-4.

13. Haider $T$, Casucci $G$, Linser T, et al. Interval hypoxic training improves autonomic cardiovascular and respiratory control in patients with mild chronic obstructive pulmonary disease. J Hypertens. 2009;27(8):1648-54.

14. Vogtel M, Michels A. Role of intermittent hypoxia in the treatment of bronchial asthma and chronic obstructive pulmonary disease. Curr Opin Allergy Clin Immunol. 2010;10(3):206-13.

15. Zhu XH, Yan HC, Zhang J, et al. Intermittent hypoxia promotes hippocampal neurogenesis and produces antidepressant-like effects in adult rats. J Neurosci. 2010;30(38):12653-63.

16. Zhang K, Zhu L, Fan M. Oxygen, a Key Factor Regulating Cell Behavior during Neurogenesis and Cerebral Diseases. Front Mol Neurosci. 2011;4:5.

17. Zhang K, Zhao T, Huang $X$, et al. Notch1 mediates postnatal neurogenesis in hippocampus enhanced by intermittent hypoxia. Neurobiol Dis. 2014;64:66-78.

18. Manukhina EB, Downey HF, Shi X, Mallet RT. Intermittent hypoxia training protects cerebrovascular function in Alzheimer's disease. Exp Biol Med (Maywood). 2016;241(12):1351-63.

19. Chang JC, Hu WF, Lee WS, et al. Intermittent Hypoxia Induces Autophagy to Protect Cardiomyocytes From Endoplasmic Reticulum Stress and Apoptosis. Front Physiol. 2019;10:995.

20. Querfurth HW, LaFerla FM. Alzheimer's disease. N Engl J Med. 2010;362(4):329-44

21. Soria Lopez JA, González HM, Léger GC. Alzheimer's disease. Handb Clin Neurol. 2019:167:231-55.

22. Brookmeyer R, Abdalla N, Kawas CH, Corrada MM. Forecasting the prevalence of preclinical and clinical Alzheimer's disease in the United States. Alzheimers Dement. 2018;14(2):121-9.

23. Grundke-lqbal I, lqbal K, Tung YC, Quinlan M, Wisniewski HM, Binder LI. Abnormal phosphorylation of the microtubule-associated protein tau (tau) in Alzheimer cytoskeletal pathology. Proc Natl Acad Sci U S A. 1986:83(13):4913-7.

24. Hardy JA, Higgins GA. Alzheimer's disease: the amyloid cascade hypothesis. Science. 1992;256(5054):184-5.

25. Lasagna-Reeves CA, Castillo-Carranza DL, Jackson GR, Kayed R. Tau oligomers as potential targets for immunotherapy for Alzheimer's disease and tauopathies. Curr Alzheimer Res. 2011;8(6):659-65.

26. Takashima A. Tauopathies and tau oligomers. J Alzheimers Dis. 2013;37(3):565-8

27. Vinters HV. Emerging concepts in Alzheimer's disease. Annu Rev Pathol. $2015 ; 10: 291-319$
28. Castillo-Carranza DL Nilson AN, Van Skike CE, et al. Cerebral Microvascular Accumulation of Tau Oligomers in Alzheimer's Disease and Related Tauopathies. Aging Dis. 2017:8(3):257-66.

29. Huang Y, Mucke L. Alzheimer mechanisms and therapeutic strategies. Cell. 2012:148(6):1204-22.

30. Borchelt DR, Thinakaran G, Eckman CB, et al. Familial Alzheimer's disease-linked presenilin 1 variants elevate Abeta1-42/1-40 ratio in vitro and in vivo. Neuron. 1996;17(5):1005-13.

31. Aso E, Lomoio S, López-González I, et al. Amyloid generation and dysfunctional immunoproteasome activation with disease progression in animal model of familial Alzheimer's disease. Brain Pathol. 2012;22(5):636-53.

32. Shapira R, Solomon B, Efrati S, Frenkel D, Ashery U. Hyperbaric oxygen therapy ameliorates pathophysiology of 3xTg-AD mouse model by attenuating neuroinflammation. Neurobiol Aging. 2018;62:105-19.

33. Guo Y, Guo H, Zhang L, et al. Genomic analysis of anti-hepatitis B virus (HBV) activity by small interfering RNA and lamivudine in stable HBVproducing cells. J Virol. 2005;79(22):14392-403.

34. Patterson TA, Lobenhofer EK, Fulmer-Smentek SB, et al. Performance comparison of one-color and two-color platforms within the MicroArray Quality Control (MAQC) project. Nat Biotechnol. 2006;24(9):1140-50.

35. Mazzetti S, Frigerio S, Gelati M, Salmaggi A, Vitellaro-Zuccarello L. Lycopersicon esculentum lectin: an effective and versatile endothelial marker of normal and tumoral blood vessels in the central nervous system. Eur J Histochem. 2004;48(4):423-8.

36. Engmann O, Giese KP. Crosstalk between Cdk5 and GSK3beta: Implications for Alzheimer's Disease. Front Mol Neurosci. 2009;2:2.

37. De Simone A, Tumiatti V, Andrisano V, Milelli A. Glycogen Synthase Kinase 33: A New Gold Rush in Anti-Alzheimer's Disease Multitarget Drug Discovery. J Med Chem. 2021;64(1):26-41.

38. Lauretti E, Dincer O, Praticò D. Glycogen synthase kinase-3 signaling in Alzheimer's disease. Biochim Biophys Acta Mol Cell Res. 1867;2020(5):118664.

39. Llorens-Martín M, Jurado J, Hernández F, Avila J. GSK-3ß, a pivotal kinase in Alzheimer disease. Front Mol Neurosci. 2014;7:46.

40. Hanger DP, Hughes K, Woodgett JR, Brion JP, Anderton BH. Glycogen synthase kinase-3 induces Alzheimer's disease-like phosphorylation of tau: generation of paired helical filament epitopes and neuronal localisation of the kinase. Neurosci Lett. 1992;147(1):58-62.

41. Magdesian MH, Carvalho MM, Mendes FA, Saraiva LM, Juliano MA, Juliano $L$, et al. Amyloid-beta binds to the extracellular cysteine-rich domain of Frizzled and inhibits Wnt/beta-catenin signaling. J Biol Chem. 2008;283(14):9359-68.

42. Green HF, Nolan YM. GSK-3 mediates the release of IL-1 $\beta$, TNF- $\alpha$ and IL-10 from cortical glia. Neurochem Int. 2012;61(5):666-71.

43. McCarty HJ, Roth DL, Goode KT, et al. Longitudinal course of behavioral problems during Alzheimer's disease: linear versus curvilinear patterns of decline. J Gerontol A Biol Sci Med Sci. 2000;55(4):M200-6.

44. Rad SK, Arya A, Karimian H, et al. Mechanism involved in insulin resistance via accumulation of $\beta$-amyloid and neurofibrillary tangles: link between type 2 diabetes and Alzheimer's disease. Drug Des Devel Ther 2018:12:3999-4021.

45. Ohm DT, Fought AJ, Martersteck A, et al. Accumulation of neurofibrillary tangles and activated microglia is associated with lower neuron densities in the aphasic variant of Alzheimer's disease. Brain Pathol. 2021:31(1):189-204.

46. Muraoka S, DeLeo AM, Sethi MK, Yukawa-Takamatsu K, Yang Z, Ko $J$, et al. Proteomic and biological profiling of extracellular vesicles from Alzheimer's disease human brain tissues. Alzheimers Dement. 2020;16(6):896-907.

47. DeTure MA, Dickson DW. The neuropathological diagnosis of Alzheimer's disease. Mol Neurodegener. 2019;14(1):32.

48. Liu L, Ding L, Rovere M, Wolfe MS, Selkoe DJ. A cellular complex of BACE1 and $\gamma$-secretase sequentially generates $A \beta$ from its full-length precursor. J Cell Biol. 2019;218(2):644-63.

49. Hampel H, Vassar R, De Strooper B, et al. The $\beta$-Secretase BACE1 in Alzheimer's Disease. Biol Psychiatry. 2021;89(8):745-56.

50. Jin M, Shepardson N, Yang T, Chen G, Walsh D, Selkoe DJ. Soluble amyloid beta-protein dimers isolated from Alzheimer cortex directly induce Tau 
hyperphosphorylation and neuritic degeneration. Proc Natl Acad Sci U S A. 2011;108(14):5819-24.

51. Kimura R, Devi L, Ohno M. Partial reduction of BACE1 improves synaptic plasticity, recent and remote memories in Alzheimer's disease transgenic mice. J Neurochem. 2010;113(1):248-61.

52. Townsend M, Qu Y, Gray A, et al. Oral treatment with a gamma-secretase inhibitor improves long-term potentiation in a mouse model of Alzheimer's disease. J Pharmacol Exp Ther. 2010;333(1):110-9.

53. Shinohara M, Tachibana M, Kanekiyo T, Bu G. Role of LRP1 in the pathogenesis of Alzheimer's disease: evidence from clinical and preclinical studies. J Lipid Res. 2017;58(7):1267-81.

54. Liu CC, Hu J, Zhao N, Wang J, Wang N, Cirrito JR, et al. Astrocytic LRP1 Mediates Brain A $B$ Clearance and Impacts Amyloid Deposition. J Neurosci. 2017:37(15):4023-31.

55. Ma Q, Zhao Z, Sagare AP, Wu Y, Wang M, Owens NC, et al. Blood-brain barrier-associated pericytes internalize and clear aggregated amyloid- $\beta 42$ by LRP1-dependent apolipoprotein E isoform-specific mechanism. Mol Neurodegener. 2018;13(1):57.

56. Storck SE, Meister S, Nahrath J, Meißner JN, Schubert N, Di Spiezio A, et al. Endothelial LRP1 transports amyloid- $\beta(1-42)$ across the blood-brain barrier. J Clin Invest. 2016;126(1):123-36.

57. Howlett DR, Richardson JC, Austin A, et al. Cognitive correlates of Abeta deposition in male and female mice bearing amyloid precursor protein and presenilin-1 mutant transgenes. Brain Res. 2004;1017(1-2):130-6.

58. Trinchese F, Liu S, Battaglia F, Walter S, Mathews PM, Arancio O. Progressive age-related development of Alzheimer-like pathology in APP/PS1 mice. Ann Neurol. 2004;55(6):801-14.

59. Lagadec S, Rotureau L, Hémar A, et al. Early temporal short-term memory deficits in double transgenic APP/PS1 mice. Neurobiol Aging. 2012;33(1):203.e1-11.

60. Fei $X$, Zhang $Y$, Mei $Y$, et al. Degradation of FA reduces $A \beta$ neurotoxicity and Alzheimer-related phenotypes. Mol Psychiatry. 2020. https://doi.org/ 10.1038/s41380-020-00929-7.

61. Yue X, Mei Y, Zhang Y, et al. New insight into Alzheimer's disease: Light reverses $A \beta$-obstructed interstitial fluid flow and ameliorates memory decline in APP/PS1 mice. Alzheimers Dement (N Y). 2019;5:671-84.

62. Peng Z, Luo Y, Xiao ZY. Angiopoietin-1 accelerates Alzheimer's disease via FOXA2/PEN2/APP pathway in APP/PS1 mice. Life Sci. 2020;246:117430.

63. Al-Chalabi A, Miller CC. Neurofilaments and neurological disease. Bioessays. 2003;25(4):346-55

64. Scherling CS, Hall T, Berisha F, et al. Cerebrospinal fluid neurofilament concentration reflects disease severity in frontotemporal degeneration. Ann Neurol. 2014;75(1):116-26.

65. Preische O, Schultz SA, Apel A, et al. Serum neurofilament dynamics predicts neurodegeneration and clinical progression in presymptomatic Alzheimer's disease. Nat Med. 2019:25(2):277-83.

66. Bacioglu M, Maia LF, Preische O, et al. Neurofilament Light Chain in Blood and CSF as Marker of Disease Progression in Mouse Models and in Neurodegenerative Diseases. Neuron. 2016;91(1):56-66.

67. Meeter LH, Dopper EG, Jiskoot LC, et al. Neurofilament light chain: a biomarker for genetic frontotemporal dementia. Ann Clin Transl Neurol. 2016;3(8):623-36.

68. Rohrer JD, Woollacott IO, Dick KM, et al. Serum neurofilament light chain protein is a measure of disease intensity in frontotemporal dementia. Neurology. 2016:87(13):1329-36.

69. Mattsson N, Cullen NC, Andreasson U, Zetterberg H, Blennow K. Association Between Longitudinal Plasma Neurofilament Light and Neurodegeneration in Patients With Alzheimer Disease. JAMA Neurol. 2019;76(7):791-9.

70. Goryacheva AV, Kruglov SV, Pshennikova MG, et al. Adaptation to intermittent hypoxia restricts nitric oxide overproduction and prevents beta-amyloid toxicity in rat brain. Nitric Oxide. 2010;23(4):289-99.

71. Meng SX, Wang B, LiWT. Intermittent hypoxia improves cognition and reduces anxiety-related behavior in APP/PS1 mice. Brain Behav. 2020;10(2):e01513.

72. Irizarry MC, McNamara M, Fedorchak K, Hsiao K, Hyman BT. APPSw transgenic mice develop age-related $\mathrm{A}$ beta deposits and neuropil abnormalities, but no neuronal loss in CA1. J Neuropathol Exp Neurol. 1997;56(9):965-73.

73. Kinney JW, Bemiller SM, Murtishaw AS, Leisgang AM, Salazar AM, Lamb BT. Inflammation as a central mechanism in Alzheimer's disease. Alzheimers Dement (N Y). 2018;4:575-90.

74. Heneka MT, Carson MJ, El Khoury J, et al. Neuroinflammation in Alzheimer's disease. Lancet Neurol. 2015;14(4):388-405.

75. McGeer PL, McGeer E, Rogers J, Sibley J. Anti-inflammatory drugs and Alzheimer disease. Lancet. 1990:335(8696):1037.

76. Pasinetti GM. From epidemiology to therapeutic trials with anti-inflammatory drugs in Alzheimer's disease: the role of NSAIDs and cyclooxygenase in beta-amyloidosis and clinical dementia. J Alzheimers Dis. 2002:4(5):435-45.

77. Etminan M, Gill S, Samii A. Effect of non-steroidal anti-inflammatory drugs on risk of Alzheimer's disease: systematic review and meta-analysis of observational studies. BMJ. 2003;327(7407):128.

78. Martyn C. Anti-inflammatory drugs and Alzheimer's disease. BMJ. 2003;327(7411):353-4.

79. McGeer PL, Guo JP, Lee M, Kennedy K, McGeer EG. Alzheimer's Disease Can Be Spared by Nonsteroidal Anti-Inflammatory Drugs. J Alzheimers Dis. 2018;62(3):1219-22.

80. Benito-León J, Contador I, Vega S, Villarejo-Galende A, Bermejo-Pareja F. Non-steroidal anti-inflammatory drugs use in older adults decreases risk of Alzheimer's disease mortality. PLoS One. 2019;14(9):e0222505.

81. Yan Q, Zhang J, Liu H, et al. Anti-inflammatory drug therapy alters betaamyloid processing and deposition in an animal model of Alzheimer's disease. J Neurosci. 2003;23(20):7504-9.

82. Zhu S, Wang J, Zhang Y, et al. The role of neuroinflammation and amyloid in cognitive impairment in an APP/PS1 transgenic mouse model of Alzheimer's disease. CNS Neurosci Ther. 2017;23(4):310-20.

83. Zheng $Y$, Wang $Q$, Xiao $B$, Lu Q, Wang $Y$, Wang $X$. Involvement of receptor tyrosine kinase Tyro3 in amyloidogenic APP processing and $\beta$-amyloid deposition in Alzheimer's disease models. PLoS One. 2012;7(6):e39035.

84. Patel NS, Paris D, Mathura V, Quadros AN, Crawford FC, Mullan MJ. Inflammatory cytokine levels correlate with amyloid load in transgenic mouse models of Alzheimer's disease. J Neuroinflammation. 2005;2(1):9.

85. Chen R, Lai UH, Zhu L, Singh A, Ahmed M, Forsyth NR. Reactive Oxygen Species Formation in the Brain at Different Oxygen Levels: The Role of Hypoxia Inducible Factors. Front Cell Dev Biol. 2018;6:132.

86. Hassan H, Chen R. Hypoxia in Alzheimer's disease: effects of hypoxia inducible factors. Neural Regen Res. 2021;16(2):310-1.

87. Thielke S, Slatore CG, Banks WA. Association Between Alzheimer Dementia Mortality Rate and Altitude in California Counties. JAMA Psychiatry. 2015;72(12):1253-4.

88. Serebrovska ZO, Serebrovska TV, Kholin VA, et al. Intermittent HypoxiaHyperoxia Training Improves Cognitive Function and Decreases Circulating Biomarkers of Alzheimer's Disease in Patients with Mild Cognitive Impairment: A Pilot Study. Int J Mol Sci. 2019;20(21):5405.

89. Wang H, Shi X, Schenck H, et al. Intermittent Hypoxia Training for Treating Mild Cognitive Impairment: A Pilot Study. Am J Alzheimers Dis Other Demen. 2020;35:1533317519896725.

90. Suzuki J. Effects of exercise training with short-duration intermittent hypoxia on endurance performance and muscle metabolism in welltrained mice. Physiol Rep. 2019;7(14):e14182.

91. Snyder B, Shell B, Cunningham JT, Cunningham RL. Chronic intermittent hypoxia induces oxidative stress and inflammation in brain regions associated with early-stage neurodegeneration. Physiol Rep. 2017;5(9):e13258.

92. Shiota S, Takekawa H, Matsumoto SE, et al. Chronic intermittent hypoxia/ reoxygenation facilitate amyloid- $\beta$ generation in mice. J Alzheimers Dis. 2013;37(2):325-33.

93. laccarino HF, Singer AC, Martorell AJ, et al. Gamma frequency entrainment attenuates amyloid load and modifies microglia. Nature. 2016:540(7632):230-5.

94. Martorell AJ, Paulson AL, Suk HJ, et al. Multi-sensory Gamma Stimulation Ameliorates Alzheimer's-Associated Pathology and Improves Cognition. Cell. 2019;177(2):256-271.e22. 
95. Hadanny A, Efrati S. The Hyperoxic-Hypoxic Paradox. Biomolecules. 2020;10(6):958.

96. Zhu LL, Zhao T, Li HS, et al. Neurogenesis in the adult rat brain after intermittent hypoxia. Brain Res. 2005;1055(1-2):1-6.

97. Bhalala US, Koehler RC, Kannan S. Neuroinflammation and neuroimmune dysregulation after acute hypoxic-ischemic injury of developing brain. Front Pediatr. 2014:2:144.

98. Halder SK, Milner R. Mild hypoxia triggers transient blood-brain barrier disruption: a fundamental protective role for microglia. Acta Neuropathol Commun. 2020;8(1):175.

\section{Publisher's Note}

Springer Nature remains neutral with regard to jurisdictional claims in published maps and institutional affiliations.

- fast, convenient online submission

- thorough peer review by experienced researchers in your field

- rapid publication on acceptance

- support for research data, including large and complex data types

- gold Open Access which fosters wider collaboration and increased citations

- maximum visibility for your research: over $100 \mathrm{M}$ website views per year

At $\mathrm{BMC}$, research is always in progress.

Learn more biomedcentral.com/submissions 